\title{
Job satisfaction among primary school personnel in Madagascar
}

\author{
Carlos Gamero Burón \\ Departamento de Estadística y Econometría, Universidad de Málaga \\ Campus El Ejido, s/n - 29013 Málaga (España). E-mail: gamero@uma.es
}

Gérard Lassibille

Institut de Recherche sur l'Economie de l'Education y Centre National de la Recherche Scientifique

Pôle AAFE - Esplanade Erasme - B.P. 26513F - 21065 Dijon Cedex (Francia). E-mail: gerard.lassibille@u-bourgogne.fr

\begin{abstract}
This article analyzes the job satisfaction of primary school teachers in Madagascar. Based on the estimation of multilevel models, low wages and problems getting paid, job insecurity, lack of in-service training, high pupil-teacher ratios, and lack of basic infrastructure and teaching materials are identified as the main reasons for dissatisfaction. Principals' control of teachers' activities also adversely affects satisfaction, suggesting that, in Malagasy schools, neither school directors nor teachers have succeeded in adopting organizational cultures based on cooperation among their members. These results are likely to stimulate debates on educational policy, both in Madagascar and in many other developing countries.
\end{abstract}

Keywords: Job satisfaction, primary education, Madagascar, multilevel models

JEL Classifications: C13, I21, I25, J28 